\title{
Application of Educational Technology in Holistic Module Learning: Citing the Practice of Shandong 271 Education Group as a Case Study
}

\author{
Guangwei Sun \\ Shandong 271 Education Group, Shandong, China
}

\begin{abstract}
With the rapid development of the Internet and other related technologies, the educational community has come to accept the use of educational technology in the classroom. Its innovation not only transforms teaching techniques but also expands students' channels and resources for learning. This article explores the use of educational technology in front-line teaching using 271BAY, an online educational platform developed by Shandong 271 Education Group. The use of 271BAY in the holistic module learning approach is discussed in detail.
\end{abstract}

Science Insights Education Frontiers 2022; 11(1):1499-1507.

Doi: 10.15354/sief.22.or007

How to Cite: Sun, G. (2022). Application of educational technology in holistic module learning: Citing the practice of Shandong 271 education group as a case study. Science Insights Education Frontiers, 11(1):1499-1507.

Keywords: Educational Technology, 271BAY, Holistic Module Learning

Correspondence to: Guangwei Sun, Shandong 271 Education Group, Shandong, China. E-mail: sdclsgw@126.com Conflict of Interests: None. 


\section{Introduction}

$\mathrm{W}$

ITHIN the context of the Internet's rapid expansion, modern educational technology has emerged as a critical vehicle for student autonomy, school teaching, and management digitalization. Modern educational technology may significantly improve learning efficacy, assist in correctly tracking students' progress through their learning activities, and give critical support for tailored learning. This article demonstrates the effective implementation of 271BAY technology in holistic module learning at Shandong 271 Education Group in China. The purpose of this paper is to describe the components and functions of 271BAY and to discuss its supportive roles in holistic module learning, using the teaching plan for Module 4, the Kingdom of the Rule of Law, in Morality and Rule of Law (a junior secondary school course) as an example.

\section{A Profile of 271BAY}

\section{What is $271 B A Y$ ?}

271BAY is a 271 Education Group-developed open, autonomous, and intelligent online learning community. It is a learning ecosystem guided by Internet thinking and supported by information technology that satisfies students' need for personalized and selfdirected study. As a product of the new era, 271BAY is always evolving, with each user serving as its producer and sharer.

By integrating Internet and information technology technologies into curriculum development, 271BAY enhances, enriches, and renovates the curricula of schools in the Shandong 271 Education Group. It effectively improves students' IT literacy and technological application skills by emphasizing comprehensive IT practical courses and AI courses. Educational practices such as maker education, interdisciplinary study, and project-based learning all contribute to the development of students' abilities to integrate resources, problem solve, and innovate.

\section{BAY's Fundamental Components}

271BAY is a critical component of the intelligent cloud platform for schools, offering a strong technological foundation for students' self-regulated learning. The 271BAY learning community is made up of three components: a task system (courses, homework, and exams); a measurement system (rules, tools, and so on); and an assessment output system (review, feedback, comments, etc.). Numerous subjects such as national culture, classroom learning, scientific and technological newsletters, physical and mental wellbeing, creative aesthetics, social practice, and self-regulation are covered.

Teachers and students can access both external teaching resources from the Internet and high-quality teaching materials posted by teachers from Shandong 271 Education Group schools via the 271BAY platform. 271BAY's multilayered resource drive 
promotes layered teaching and student autonomy. 271BAY facilitates students' individual search for and integration of learning resources, stimulates their autonomous learning and inquiry, and encourages them to collaborate with like-minded peers and share learning outcomes willingly.

Nan Zhao, Xinyi Zhou, Bo Liu, and Wei Liu (2020) report in their study that modern educational technology can accurately record any data in all teaching activities according to educators' and students' needs and conduct in-depth analysis of teaching practice to help educators make more scientific teaching decisions. 271BAY maintains a comprehensive record of pupils' learning and growth. It assists students in developing a growth model based on data analysis by gathering classroom data, after-class learning data, and life and health data.

The growth of students is dynamically shown through various digital records, and real-time outcome assessment is provided via the network. Throughout this process, parents can monitor their children's development in real time, getting statistics on their growth that they can use to guide their children's development.

\section{BAY's Fundamental Functions}

\section{Supporting Students’ Personalized Development}

Existing research demonstrates that educational technology is critical for raising students' academic levels. It has the potential to successfully reorganize and combine fragmented educational data, diversify instructional practices, and establish classroom patterns that better fit students' individual requirements (Xia \& Li, 2020). 271BAY's ultimate mission is to make individualized learning accessible to every student. It strives to accommodate the diverse learning needs of all students, to enhance the learning experience, and to provide a more equitable and effective quality education system. 271BAY enhances the learning environment and transforming student learning processes, 271BAY enhances the mobile Internet and information technologies. As a result, children can learn independently and effectively, and instruction can be made more engaging and effective.

Using the Internet, the Internet of things, mixed reality, and artificial intelligence, 271BAY collects instantaneous academic, behavioral, and emotional data from students in order to create a thorough picture of their evolution. Additionally, it may be used to develop a self-adaptive learning system based on large data and extensive curriculum resources, as well as generate individualized learning environments and evaluation systems.

\section{Facilitating Teachers' Development}

Teachers are the pioneers and architects of 271BAY's growth. They learn and benefit from it, as well as contribute to its creation. Teachers can enhance their selfmanagement abilities, innovative capacity, and information technology literacy by en- 
gaging in 271BAY research and development and by implementing 271BAY technology. Teachers may construct an online learning community with the support of 271BAY, develop a new data-driven teaching and research model, and become explorers and practitioners of competence-based education and teaching.

Tian et al. (2021) argue in their study that educational technology can aid in the development of a comprehensive and objective assessment model by continually stimulating teachers' enthusiasm for their work, encouraging teachers to improve the quality of their teaching and research, and cultivating teachers' dispositions toward selfdiscipline and introspection. With the assistance of 271BAY, a profile of teachers' development can be established based on data on teachers' educational and teaching practices and outcomes, as well as teachers' research and training, thereby assisting in the improvement of teacher performance assessment and upgrading mechanisms, as well as cultivating teachers' willingness and abilities for lifelong learning in their professional development.

\section{Promoting Intelligent School Administration}

271BAY integrates "intelligent education" into the school administration's overall planning and provides extensive and effective links between educational and social databases, thereby expanding the space and time available for education. It accelerates the development of digital campuses in Shandong 271 Education Group schools and promotes the adoption of digital applications on campus.

The school administration system can be improved based on Internet attitudes and information technology. Networks and intelligent terminals are used to manage the office. All evaluations of project management are created automatically, resulting in significantly increased administrative efficiency.

271BAY advances the educational management system in the Shandong 271 Education Group, raises the group's level of modernity, and provides the groundwork for a large-scale worldwide education group.

\section{BAY and Holistic Module Learning}

Holistic module learning is a student-centered instructional methodology that divides learning materials into big modules rather than discrete and fragmented courses and integrates learning content and activities into a holistic process. It is characterized by task-based learning, situational experience, autonomous inquiry, and promotive transfer. Its objective is to cultivate students' capacity for self-directed learning and inquiry through an integrated cognitive process that includes self-directed study, dialogue, criticism, application, and generation. In general, the classroom technique for holistic module learning consists of four stages: overall perception, inquiry and construction, application and transfer, and reconstruction and expansion.

In practice, combining 271BAY with holistic module learning boosts students' learning autonomy even further. 271BAY is a coordinated, open, autonomous, and in- 
telligent learning community that exists both online and offline. With teachers uploading module learning programs to an online platform, the traditional mode of instruction in which teachers assist students in constructing the knowledge structure is replaced by one in which students construct the structure independently, and the teacher-controlled learning process is transformed into self-regulated progress. Students can now tailor their resources and learning progress to their individual needs.

\section{A Case of 271BAY Supporting Holistic Module Learning}

Using module four, the Kingdom of the Rule of Law, from Morality and the Rule of Law (Volume 2 in Grade 7), we demonstrate how Shandong 271 Education Group, with the support of 271BAY, implements holistic module learning to promote students' selfdirected learning and inquiry competencies.

\section{Learning Situation Analysis and Contents of the Mod- ule}

\section{Analyze the Learning Situation}

Grade 7 is a critical stage in the development of students' moral and legal consciousness. Students in junior middle school have heard about the country's rule of law but have had limited opportunity to practice and participate in it. They have a limited understanding of how the law is formulated and how it functions. Teachers should respect students' prior life experiences, establish a good classroom learning environment, and assist them in constructing new ones based on their qualities and cognitive abilities.

Module four begins with the recently enacted Civil Code of 2021 in order to evaluate the genesis, function, and application of the law. Students are prompted to examine topics that are directly relevant to reality, such as objects hurled from high buildings or whether or not to assist a fallen elderly person, using Civil Code regulations as a guide. Consideration and comprehension of the means by which laws are implemented contribute to their increasing knowledge of morality and the rule of law and to the formation of moral and legal habits. This enables students to develop into competent citizens in the future. In this way, the whole module design is used to accomplish educational objectives within the overarching concept of the rule of law.

\section{Contents of the Module}

The Kingdom of the Rule of Law module covers the qualities of law, its role, the importance of the rule of law, the specific legal protection afforded to minors, and the imperative that pupils have an awareness of the rule of law. As a result, the module's central idea is the rule of law, from which all other concepts in this course are derived, including patriotism, equality, freedom, justice, and harmony. 
The following four learning objectives are underlined for students in this module:

- $\quad$ Create a mind map focused on the Kingdom of the Rule of Law, summarize fundamental concepts such as the nature and purposes of law, legal protection for children, and the prerequisites of the rule of law, and explain a rudimentary grasp of law using real-world examples.

- Using 271BAY materials, investigate and summarize the importance of the rule of law in personal, societal, and national development, as well as the unique requirements for people and nations in terms of the rule of law.

- Make some fair proposals for the rule of law in order to aid in the establishment of the rule of law in China.

- $\quad$ Reconstruct the Kingdom of the Rule of Law's mental map from three perspectives: what, why, and how to do, and be able to apply the law to realworld problems.

After establishing objectives, this module's learning proceeds through the procedural stages of overall perception, inquiry and construction, application and transfer, and reconstruction and expansion. Each step has a distinct objective. We focus on overall perception in this paper in order to demonstrate how students learn about the qualities and functions of law, as well as the significance and requirements of the rule of law, and to construct a knowledge structure for this module using 271BAY technology.

\section{Learning Procedure}

At the stage of overall perception, students begin by learning that the law is inextricably linked to our daily lives and then gradually delve deeper into the sources, characteristics, functions, and requirements of the law. Through the use of concrete examples, it is vital to assist pupils toward an understanding of the significance and value of the law to people, society, and the nation. By analyzing specific legal provisions and situations, students gain a better understanding of the importance of the law and the rule of law, thus increasing their awareness of the rule of law and their engagement in public affairs.

\section{Preparation before Class with the Aid of 271BAY}

- $\quad$ Students are asked to undertake advance research on legal topics on weekends using the provided 271BAY materials, which include films of Civil Code legal provisions and their interpretation and execution. They can submit questions via the 271BAY platform's "My Questions" option, which will be collected by teachers prior to class.

- Before class, students are divided into study groups, and the course monitor and group leaders are instructed. The course monitor's responsibility is to remind classmates to prepare for class by reading the assigned texts and other 271BAY materials distributed by teachers. The specialist study group leader 
is responsible for collecting questions and issues of interest for teachers regarding this module and communicating them to group members.

\section{Classroom Activities Supported by 271BAY}

According to constructivist learning theory, the purpose of education is to aid students in constructing new experiences from previous ones. Teachers develop learning settings for the module of Kingdom of Rule of Law in the light of the new Civil Code's promulgation and supplement classroom activities with extensive resources from 271BAY.

- Activity number one is a competition of legal knowledge in real life.

- Each student gathers at least five existing laws and two well-known cases over the course of a weekend through internet research, visits, and interviews.

- Students present and explain their understanding of the efforts made in recent years to promote the rule of law in China.

Students attempt to comprehend the role of the law through the examination of individual legal instances and legal provisions. For example, the Law on the Protection of Minors and the Law on the Prevention of Juvenile Delinquency are two unique laws aimed at protecting minors, demonstrating the intimate connection between laws and life. The study group leader organizes group members to show gathered legal provisions, rule of law stories, pertinent instances, and their interpretations on the 271BAY platform, which students use to develop an initial impression of the function of law in their lives.

\section{- Activity two: Literature review and intensive reading}

A preliminary understanding of the entire module is achieved through rigorous reading of the textbook and resources from 271BAY, as well as through group discussion, intergroup interchange, and teacher commentary. Students identify critical and difficult aspects and establish their own judgments during this process. Their capacity for selfdirected learning is significantly enhanced. By now, students should be able to comprehend the major concept of "rule of law" in this module using their own examples and terminology, as well as identify the characteristics and roles of law, the requirements and relevance of the rule of law, and the specific protection for minors in China.

\section{- Construction of a Mind Map Is the Third Activity.}

Due to students' difficulty in articulating the relationships between law and the rule of law, personal behavior and the rule of law, and the rule of law and the rule of virtue, teachers designed activity three to guide students through the processes of independent review, group cooperation, display and sharing, and exchange and supplementation. The mind map should be centered on the major concept of the rule of law, with examples and a knowledge structure of at least three levels, preferably included.

During this procedure, the study group leader will lead the group in discussing, exchanging, supplementing, and improving the mind map, as well as photographing and 
uploading the enhanced mind map to the 271BAY platform. Thus, the mind map can be compared to those of other groups and adjusted as a result of group discussion. Students obtain a general understanding of the curriculum with this task.

\section{- Passing the preliminary examination}

Teachers recommend that students complete the 271BAY-sponsored test and check their scores online to measure their understanding of basic topics in this module. Passing the test indicates that you have a firm grasp of the fundamental concepts and are prepared to go on to the next stage of study.

\section{Conclusions and Prospective}

In the case study, the importance of 271BAY in holistic module learning is well demonstrated: 271BAY enhances students' learning interests and diversifies learning activities, resulting in the substitution of active inquiry for passive learning. 271BAY's extensive learning tools extend students' horizons, allowing them to construct a holistic knowledge structure. The use of 271BAY allows for more efficient interactions between students and teachers, as teachers can always provide students with timely feedback.

The addition of technology to classroom teaching does not constitute a merger of online and offline education. 271BAY supports holistic module learning by maximizing the benefits of online resources and mobilizing students' initiative to make learning more efficient and lively.

Nonetheless, we continue to value the benefits of traditional learning techniques characterized by instructor guidance, motivation, and oversight. In the future, when designing and implementing 271BAY technologies, we will stick to the philosophy of combining the strengths of both traditional and digitalized learning modes. Although there is a strong movement toward transitioning to a student-centered class, the teacher-dominated class is still prevalent in Shandong 271 Education Group. We're still looking into how well the two modes can work together. The creation of the 271BAY learning community was a successful attempt to find a balance between these two types of instruction. Shandong 271 Education Group is dedicated to helping kids improve their self-control in school and in life. On the other hand, absolute autonomy in learning may impede pupils' systemic mastery of knowledge. In this context, educational technology can be used to regulate and change the degree of autonomy of students and teachers, as well as assign different control powers to students and teachers based on certain learning activities. Shandong 271 Education Group schools will do additional research in this area. 
Sun (China). Application of Educational Technology in Holistic Module Learning.

\section{References}

Li, X. \& Xia, J. (2020). School-based practice based on supplemental instruction of big data in education. Science Insights Education Frontiers, 7(2): 913-933. DOI:

https://doi.org/10.15354/sief.20.or063

Tian, J., Mao, W., Liao, L. \& Zhou, X. (2021). Targeted poverty alleviation model of China's online education based on "Triple Classroom": Take the "Shi Shi Xiang Yun" online school in Chengdu, China as an ex- ample. Science Insights Education Frontiers, 9(1):1183-1197. DOI:

https://doi.org/10.15354/sief.21.re035

Zhao, N., Zhou, X., Liu, B., \& Liu, W. (2020).

Guiding teaching strategies with the education platform during the COVID-19 epidemic: Taking Guiyang No. 1 Middle School teaching practice as an example. Science Insights Education Frontiers, 5(2):531-539. DOI: https://doi.org/10.15354/sief.20.rp005

Received: 10 January 2022

Revised: 26 January 2022

Accepted: 3 February, 2022 